\title{
Higher order conditioning of a taste aversion
}

\author{
NIGEL BOND and WAYNE HARLAND \\ School of Behavioural Sciences, Macquarie University, North Ryde, New South Wales 2113, Australia
}

\begin{abstract}
Two groups of rats each received 5 drops of $\mathrm{NaCl}$ solution from a dropper placed directly inside the mouth. The experimental group was then injected with lithium chloride to establish a conditioned taste aversion. The control group was injected $24 \mathrm{~h}$ later. After a recovery day the above procedures were repeated. On the next day both groups received 5 drops of a saccharin solution followed immediately by 5 drops of the $\mathrm{NaCl}$ solution. Subsequent preference tests established that the experimental group had learned an aversion to the saccharin solution as a result of its pairing with the $\mathrm{NaCl}$ solution which had previously been associated with poisoning. These results demonstrate that higher order conditioning of a taste aversion can be established using tastes as both the first-order stimulus and the second-order stimulus.
\end{abstract}

Rats will learn to suppress their intake of a distinctive flavored solution if their initial exposure to that solution is associated with sickness (Revusky \& Garcia, 1970). These taste aversions can be learned despite long delays between the CS (taste) and the US (poisoning), even when only a single trial is employed (Smith \& Roll, 1967). Other parametric studies have demonstrated that the magnitude of the aversion varies directly with the concentration of the CS (Dragoin, 1971), and of the US (Revusky, 1968).

In a recent paper, Best, Best, \& Mickley (1973) demonstrated that rats will avoid drinking a solution associated with placement in a compartment where they had previously been made ill. The compartment had become a conditioned reinforcer for taste aversion learning, and the phenomenon they had demonstrated was that of higher order conditioning (Pavlov, 1927).

The first-order stimulus Best et al. (1973) employed, i.e. the distinctive compartment, was an "exteroceptive". stimulus and thus did not differ from the stimuli usually employed in such experiments. The present experiment was designed to investigate whether a taste, i.e. an "interoceptive" stimulus, previously paired with illness, could function as the effective first-order stimulus in a higher order conditioning paradigm. One problem with such an experiment is that animals avoid drinking a solution that has been previously associated with poisoning, and as a result may not even taste it. However, since approach and consumption of the solution are not necessary for establishing a taste aversion (Domjan \& Wilson, 1972), this problem was overcome by employing small volumes of solution placed directly inside the animal's mouth with an eyedropper (cf. Peck \& Ader, 1974).

\section{METHOD}

Subjects and Apparatus. Twenty-four male Wistar rats weighing between $225 \mathrm{~g}$ and $333 \mathrm{~g}$ were used. The subjects were

The authors wish to thank E. Backhouse for hif valueble technical assistance and Dr. E. DiGiusto for his helpful comments during the preparation of the manuscript. Reprints may be obtained from Nigel Bond, School of Behavioural Sciences, Macquarie University, North Ryde, New South Wales 2113, Australia. housed in pairs in wire cages (15 $24 \times 20 \mathrm{~cm}$ high) with free access to food for the duration of the experiment. Subjects were given access to water in separate drinking cages. These drinking cages were similar in dimensions to the home cages, but different in that a $50 \mathrm{ml}$ graduated Richter tube could be inserted into either end of the cage. No food was available in the drinking cages.

Procedure. On each of the first eleven days, individual subjects were given access to water for $10 \mathrm{~min}$ per day. The water bottle was placed on opposite ends of the drinking cage on alternate days to train the animals to seek fluid from both ends.

On Day 5 , the animals were weighed and then allowed access to water for $10 \mathrm{~min}$. Four hours later, subjects from the experimental group each received five drops (approximately $0.1-0.2 \mathrm{ml}$ ) of a $0.12 \mathrm{M} \mathrm{NaCl}$ solution from a dropper placed just inside the animal's mouth. This was followed immediately by an intraperitoneal injection of $10 \mathrm{ml} / \mathrm{kg}$ of $0.3 \mathrm{M}$ lithium chloride. The control group received five drops of the $\mathrm{NaCl}$ solution but were not injected until the following day, when they received an injection of lithium chloride $4 \mathrm{~h}$ after their 10 min drinking period. On Day 7 both groups received only their 10 min water ration.

On Days 8, 9, and 10 the two groups were exposed to exactly the same procedures as on Days 5, 6, and 7; i.e., the experimental group was injected immediately after receiving the $\mathrm{NaCl}$ solution, whereas the control group was injected $24 \mathrm{~h}$ later. ${ }^{\prime}$

On Day 11 both groups of animals received $10 \mathrm{~min}$ access to water; then, $4 \mathrm{~h}$ later, each received five drops of an $0.25 \%$ saccharin solution from the dropper followed immediately by five drops of the $\mathrm{NaCl}$ solution.

Starting with Day 12, preference for the saccharin solution versus water was measured in four daily 10 -min preference tests. The position of the two solutions was alternated on succeeding days, and saccharin preference was measured as the percentage of total fluid intake.

\section{RESULTS AND DISCUSSION}

The results are summarized in Figure 1. It is apparent that the experimental group learned an aversion to the saccharin as a result of its pairing with the $\mathrm{NaCl}$ solution which had previously been associated with poisoning. This was confirmed by an overall two-way analysis of variance which revealed both a significant group effect $(F=4.95, \mathrm{df}=1 / 21, \mathrm{p}<.05)$ and a significant test day effect $(F=6.73$, df $=3 / 63, p<.001)$. There was also a significant Group by Test Day interaction $(F=3.71$, $\mathrm{df}=3 / 63, \mathrm{p}<.025$ ). Mann-Whitney $\mathrm{U}$ tests (one-tailed) 


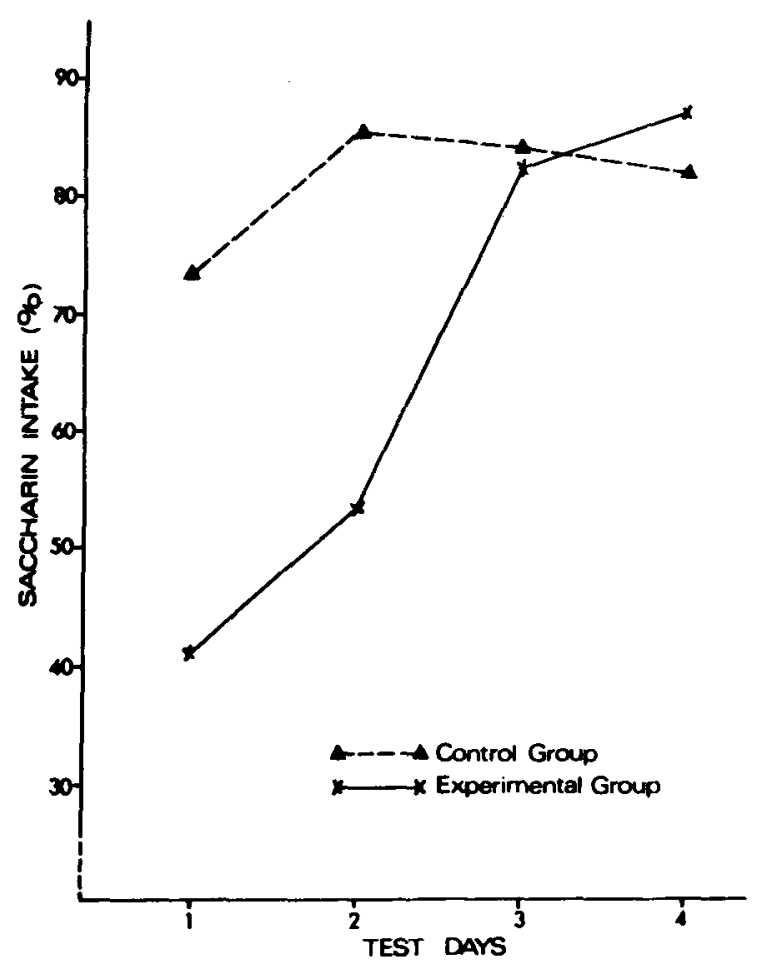

Figure 1. Mean saccharin preference for each group on each test day.

yielded significant differences between the two groups on Day $1 \quad(U=30.5, \mathrm{p}<.05)$ and Day $2(U=25$, $p<.01)$. There were no significant differences on Days 3 and 4.

These results provide a clear demonstration of the higher order conditioning of a taste aversion. The experimental group displayed a lower preference for the saccharin than the control group on each of the first two days. By Day 3, the aversion had extinguished. This effect was obtained with only one pairing of the saccharin and $\mathrm{NaCl}$ solutions even though the volumes of solution consumed were small compared to those usually employed in taste aversion experiments. In this respect the present finding further demonstrates the rat's extreme sensitivity to the pairing of tastes and poisoning or, as in the present case, a taste and a stimulus associated with poisoning.

In both the present study and that of Best et al. (1973) the animal was exposed to the first-order stimulus immediately after exposure to the second-order stimulus. It will be of interest to determine whether higher order conditioning can be obtained even when there is an appreciable delay between CS1 and CS2, as in typical taste aversion learning. Further, it remains to be seen whether higher order conditioning in taste aversion learning will display similar properties to those demonstrated by Rescorla (1973) using a fear conditioning procedure. For example, Rizley and Rescorla (1972) have demonstrated that higher order fear conditioning is unaffected by extinction of the first-order stimulus on which it is based. Similarly, Rescorla (1973) has found that habituation of the US attenuated the response to the first-order, but not to the second-order stimulus. Certainly, the ease with which higher order conditioning was obtained in the present experiment suggests that the taste aversion paradigm may prove useful for the subsequent study of this important phenomenon.

\section{NOTE}

It should be noted that the aversion to the $\mathrm{NaCl}$, based on the first-order conditioning trials, was not tested for. We wished to keep the procedure as simple as possible, and previous research had indicated that an aversion was acquired under the present conditions.

\section{REFERENCES}

Best, P. J., Best, M. R.. \& Mickley, G. A. Conditioned aversion to distinct environmental stimuli resulting from gastro-intestinal distress. Journal of Comparative and Physiological Psy chology, 1973, 85, 250-257.

Domjan, M., \& Wilson, N. Contributions of ingestive behaviors to taste-aversion learning in the rat. Journal of Comparative and Physiological Psychology, 1972, 80, 403-412.

Dragoin, W. B. Conditioning and extinction of taste-aversions with variations in intensity of the CS and US in two struins of rats. Psychonomic Science, 1971, 22, 303-305.

Pavlov, I. P. Conditioned reflexes. (Translated by G. V. Anrep) London: Oxford University Press, 1927.

Peck, J. H. \& Ader, R. Illness-induced taste-aversion under states of deprivation and satiation. Animal Leaming \&ehavior. $1974,2,6-8$.

Rescorla, R. A. Effects of US habituation following conditioning. Joumal of Comparative and Physiologica Psy chology, 1973, 82, 137-143.

Revusky, S. H. Aversion to saccharin produced by contingent X-irradiation: Temporal and dosage parameters. Joumal of Comparative and Phy giological Psy chology, 1968, 65, 17-22.

Revusky, S. H., \& Garcia, J. Learned associations over long delays. In G. H. Bower \& J. T. Spence (Eds.), The psychology of learning and motivation: Aduances in research and theory. Vol. 4. New York: Academic Press, 1970.

Rizley, R. C., \& Rescorla, R. A. Associations in second-order conditioning and seneory pre-conditioning. Journal of Comparative and Physiological Psy chology, 1972, 81, 1-11.

Smith. J. C. \& Roll, D. L. Trace conditioning with X-rays as an aversive stimulus. Psychonomic Science, 1967, 9, 11-12.

(Received for publication December 18, 1974. Revision received March 19, 1975.) 